\title{
Wild trees in the Amazon basin harbor a great diversity of beneficial endosymbiotic fungi: Is this evidence of protective mutualism?
}

Gazis, Romina ${ }^{1}$ and Chaverri, Priscila ${ }^{2,3}$

${ }^{1}$ Clark University, Biology Department, 950 Main Street, Worcester, Massachusetts 01610, U.S.A.

${ }^{2}$ University of Maryland, Department of Plant Science and Landscape Architecture, 2112 Plant Sciences Building, College Park, Maryland 20742, U.S.A.

${ }^{3}$ Universidad de Costa Rica, Escuela de Biología, Apartado11501-2060, San Pedro, San José, Costa Rica

Article history:

Received 02 December 2014

Revision received 16 March 2015

Accepted 27 March 2015

Corresponding editor:

Tom Bultman

Corresponding author: rgazis@clarku.edu

\begin{abstract}
:
It has been shown that the disappearance or drastic changes in ancestral and indigenous (or native) endosymbiotic microbiota can lead to many adverse health consequences. However, the effects of changes in beneficial endosymbionts in plants are poorly known (except for mycorrhizal and rhizobial associations). We sampled and compared endophytes from hundreds of trees belonging to the economically important genus Hevea, the source of natural rubber, in their native range in the Amazon basin and in plantations. We also conducted antagonism tests to
\end{abstract}


determine the potential some of these endophytes may have on selected plant pathogenic fungi. The natural and indigenous endosymbiotic mycota of the rubber tree (Hevea) contains a high diversity of beneficial fungi that may be causing a protective effect against pathogens (protective mutualism). In contrast, plantation trees have a reduced and different diversity of these beneficial fungi. We propose that abundance, and not just presence, of competitive fungal strains and species (i.e., Trichoderma and Tolypocladium) is creating a protective effect against pathogens in wild trees. This study provides support for the importance of mutualistic endosymbionts in plant health and ecosystem resilience, and calls for awareness of their potential loss by human-related activities.

Keywords: biodiversity, biological control, Hevea, natural rubber, tropical forest conservation

\section{Introduction}

Many studies have revealed that reduction or removal of natural endosymbiotic microbiota can adversely affect the health of their host. This protective mutualism conferred by the host's endosymbiotic community has been reported for many organisms, ranging from plants to humans. One example is the correlation between decrease in disease incidence and the diversity of existing symbionts within mammals' gut ecosystems (Round and Mazmanian, 2009). Similar improvement in host fitness has been reported for insects, in which endosymbiotic species of Burkholderia are acquired horizontally every generation (Kikuchi et al., 2007). Even in humans it has been shown that the disappearance of ancestral indigenous commensal microbiota, which is intimately involved in human physiology, is not beneficial and may have many health consequences (Sears, 2005; Blaser and Falkow, 2009).

Protective mutualism conferred by horizontally transmitted microbes has been poorly studied in plants (except for mycorrhizal or rhizobial associations), especially in their native environments (Evans et al., 2003; Berlec, 2012). Horizontal transmission refers to that which occurs among individuals through spores or other ex planta propagules; this is in comparison to vertical transmission, which occurs from parent to progeny (Rodriguez et al., 2009). Even though an incredible diversity of horizontally transmitted endosymbiotic fungi (a.k.a. endophytes) has been reported for almost every plant studied, their functions are mostly 
unknown. There is evidence that some of these endophytes provide benefits to the plant (e.g., drought resistance, induced resistance to pathogens, and antiherbivory, among others) while others may be detrimental (e.g., latent pathogens) (Saikkonen et al., 1998; Arnold et al., 2000; Rodriguez et al., 2009). However, because most of these studies have characterized endophytes in plants away from their natural habitats (Arnold and Herre 2003, Rubini et al., 2005, SaucedoGarcia et al., 2014), very little is known about their diversity and function in their native ecosystems, especially in tropical forests.

To begin to shed light on the potential effects of land-use changes (i.e., monoculture plantations) on beneficial fungal endosymbionts, we compared the diversity of endophytic fungi in plantations and in wild trees of the economically important tropical tree, Hevea brasiliensis (Euphorbiaceae) within and outside its native range. Hevea brasiliensis is the source of natural rubber and is native to the Amazon basin (Shultes, 1970) but planted extensively in Asia and Africa. Because horizontally transmitted endophytes in general are absent from seeds, once those seeds are transported from the wild and introduced to different habitats, they would likely be exposed to a different community of endophyte species, possibly excluding many coevolved or indigenous beneficial species (Evans et al., 2003; Evans, 2008). The premises guiding our study were: (a) the endophyte diversity in wild rubber populations is different to that in plantation trees, because infection by horizontally transmitted endophytes depends on the availability and viability of fungal propagules (e.g., spores) in the surrounding environment; (b) wild trees will harbor a greater number of potentially mutualistic endophytes because these endophytes have coevolved or lived associated with their host longer than those in plantations; (c) trees growing in plantations will have more endophytes with potential to be pathogenic than wild trees because natural enemies (or antagonists) would be less frequent or absent; and (d) selected endophytic strains have antifungal properties against plant diseases. To test these premises, we compared the fungal endophytic community inhabiting the leaves and sapwood of wild and planted rubber trees within and outside its native range in the Amazon basin. We also conducted tests to determine the antagonistic potential that some of these endophytes would have against plant pathogenic fungi. This study provides support for the addition of mutualistic endosymbionts to the list of ecological services provided by natural forests, their importance in plant health and ecosystem resilience, and calls for awareness of their potential loss by human-related activities.

\section{Materials and methods}




\section{Tree data and endophyte collection}

A total of 190 Hevea trees were located in eight different localities, in seven of the localities populations of $H$. brasiliensis were sampled, and in one locality (Los Amigos, LA) the sister species H. guianensis was sampled. Data for each tree was annotated, i.e., GPS coordinates, elevation, diameter at breast height ( $\mathrm{dbh}$ ) and height. Trees were distributed under two types of management: wild or plantations. Wild trees refer to Hevea trees found growing naturally within its native habitat, whereas planted (= managed) trees refer to Hevea trees growing under monoculture conditions. Table S1 shows the collections sites and their respective number of samples, Table S2 shows environmental data for each site, and Table S3 shows the height and diameter for the wild populations of trees. Fungal endophytes were collected from living leaves and sapwood tissue. Collection protocols are fully described in Gazis and Chaverri (2010), but a summarized description follows. Three segments of $c a .3 \times 3 \mathrm{~mm}$ from each leaflet were surfacesterilized through sequential immersion in 2\% (v/v) sodium hypochlorite (bleach) solution, $70 \%$ (v/v) ethanol, and sterilized water, and placed onto CMD $+\left(\mathrm{BBL}^{\mathrm{TM}}\right.$ corn-meal-agar $+2 \%$ dextrose + antibiotic). To isolate endophytes from stems, living sapwood was exposed on three areas of the stem and in each of those areas three pieces of $c a .5 \times 2 \mathrm{~mm}$ of living sapwood tissue were excised and transferred immediately to Petri plates containing $\mathrm{CMD}+$. An antibiotic solution (1\% solution of Neomycin-Penicillin-Streptomycin, Sigma-Aldrich, St. Louis, MO, USA) was added to the media to eliminate bacterial endophytes. The plates were incubated for several days (up to 2 months) and the emerging colonies were subcultured to obtain pure isolates.

\section{DNA extraction, amplification, and sequencing}

Individual isolates were grown in Difco ${ }^{\mathrm{TM}}$ potato-dextrose-broth (PDB) at $25^{\circ} \mathrm{C}$ for up to 2 weeks, depending on their growth rate. Genomic DNA was extracted from the mycelial mat using a Power Plant ${ }^{\mathrm{TM}}$ DNA isolation kit (MO BIO Laboratories Inc., Solana Beach, CA, USA). The Internal Transcribed Spacer (ITS) and a region of the Large Subunit (LSU) of the nuclear ribosomal DNA were amplified in one reaction, using the ITS5 and LR5 primers (White et al., 1990). Even though the ITS can give an approximate species identification (at least to the level of a species complex), it has been shown that it is not appropriate for Trichoderma and that introns of translation elongation factor $1 \alpha$ locus (tefl) are a better tool for identifying species (Chaverri et al., 2015). Due to the importance of this genus for this project, we additionally sequenced the tefl region ( $\sim 500 \mathrm{bp}$ ), using the ef728M and ef2 primers (Carbone and Kohn 1999; 
Rehner 2001). Refinement in the definition of other fungal species found here could be done in future studies. PCR reactions and conditions for the ITS marker and for the tefl are fully described in Gazis and Chaverri (2010) and in Chaverri et al. (2015). PCR products were cleaned using ExoSAP-IT® (USB Corporation, Cleveland, OH, USA) and sequenced at MCLAB laboratories (www.mclab.com).

\section{DNA sequence processing, grouping, and taxonomic attribution}

Sequencher ${ }^{\mathrm{TM}}$ ver. 4.9 (Gene $\operatorname{Codes}(\mathrm{C}$, MI, USA) was used to assess the quality of sequence chromatograms and to edit them when necessary. Sequences were aligned using MAFFT version 6 with the E-INS-i strategy (Katoh and Hiroyuki, 2008). Alignments were visualized using MESQUITE version 7.2 (Maddison and Maddison, 2009) and the 5' and 3' ends were trimmed to a uniform length. Complete ITS sequences were clustered into putative species or "Operational Taxonomic Units" (OTUs) using the furthest neighbor algorithm implemented in Mothur (Schloss et al., 2009). Sequences with a $99 \%$ similarity in ITS sequence were assigned to the same OTU. We used a 99\% similarity threshold based on previous studies that demonstrated a low ITS sequence variability in many fungal endophyte groups (Rojas et al., 2010; Gazis et al., 2011). Isolates were identified to the genus rank using the BLASTn algorithm implemented in GenBank (www.ncbi.nlm.nih.gov/BLAST). The average sequence length submitted as query was $\sim 500-600$ bp (ITS1 + 5.8 + ITS2), and the minimum sequence coverage was set to $90 \%$. Matches that had $95 \%$ or more ITS similarity, belonging to ex-type cultures or published studies, were considered reliable. Trichoderma isolates were identified using the tef1 region. Sequences for representative OTUs were deposited in GenBank (Table S4).

\section{Statistical analyses}

Once all sequences were grouped into OTUs, their frequency (= abundance) at each locality was measured. We compared the number of species and isolate abundance in relation to their management type (wild or planted) and tissue of origin (sapwood or leaf). The KolmogorovSmirnov test revealed that the data were not normally distributed, non-parametric tests were used

for all comparisons. For the first set of comparisons, replicates (individual trees) were separated into two groups: group 1 = wild, group 2 = plantation. To assess if there was a significant difference between management types in the number of species, the overall abundance and in the abundance of specific genera, a non-parametric equivalent of the t-test (Mann-Whitney $U$ test) was performed. To avoid the increase of family-wise error due to multiple comparisons, only 
genera with an isolate abundance of more than 40 were used. For the groups of endophytes that showed significant results, differences in the leaf or the sapwood community or in both were also tested for. For the latter, multiple comparisons were performed through a non-parametric equivalent of the ANOVA (Kruskal-Wallis test). Sample units were segregated into subsamples coming from leaves (wild or planted) or sapwood (wild or planted). Finally, correlation between tree height and diameter and the number of species and abundance, was tested using field data collected in wild localities and the non-parametric test, Spearman's rho. All statistical tests were performed in SPSS ver. 13.0 and the $p$-value was corrected for multiple comparisons (Bonferronis' correction).

Analysis of similarities (ANOSIM) based on 1000 permutations was used to check for management type difference in respect to community composition. Additionally, plots based on Non-metric Multidimensional Scaling (NMDS) and Principal Coordinate Analysis (PCoA), were produced to visualize the aggregation of the trees based on their generic and ecological composition. Four datasets were constructed: (1) complete dataset from all eight localities, (2) all localities minus data from Cameroon, (3) all localities minus data from Cameroon and Mexico, and (4) only data from $H$. brasiliensis distributed within its native range. These datasets were constructed to evaluate the robustness of the results at different geographical scales. The three mentioned statistical analyses were run using the software PAST ver. 3.04 with Bray-Curtis distance (Hammer et al., 2001). Differences in community composition were also evaluated based on phylogenetic information. Fast UniFrac (http://unifrac.colorado.edu) was used to determine if the two management types (wild vs. plantation) had significantly different endophytic communities (Hamady et al., 2010). A phylogenetic tree containing all endophyte sequences was used as the input. Due to the high number of sequences, a distance tree (Neighbor Joining) was built with MAFFT using the complete amplicon (ITS1+5.8S+ITS2+partial LSU). A weighted UniFrac significance was run with 1000 permutations and normalized abundances.

\section{Species accumulation curves and sample size coverage}

Species accumulation curves for each locality were created in EstimateS ver. 7.5 (Colwell, 2005) using Mothur $99 \%$ ITS sequence similarity OTU groups. Species accumulation curves were randomized (using 1000 randomizations without replacement) to create "smooth curves." To avoid any influence of density on the comparisons between localities, significant differences on the number of isolates obtained by each sample size were checked for (Colwell et al., 2004). 
Graphics were created using SPSS ver. 13.0. Sample size coverage was estimated following Chao et al. (2009).

\section{Ecological analyses}

To investigate if there was a trend in the abundance of strains of specific ecological roles in relation to the type of management, a putative ecological role was assignedto each of the OTUs that were identified to genus. "Ecological role" was defined as the nutritional mode and possible or hypothesized relationship that an organism has with its host or with the other members of the endophytic community. This assignment was based on published literature and on the USDAARS database (Farr and Rossman, 2012). Genera were assigned to one of the following putative ecological roles: (1) plant pathogen, (2) saprobe, (3) mycotroph (feeds on or parasitizes other fungi), or (4) entomopathogen (feeds on or parasitizes insects) (Table S5). The putatively plant pathogenic species may include those that are also facultative pathogens with a saprotrophic stage. Those labeled as "saprobes" included species that have never been reported as plant pathogens. In cases where isolates belonged to genera for which more than one ecological role has been reported (e.g., Trichoderma spp. have been reported as saprobes and mycotrophs), ecological role was assigned based on the closest species match using the BLAST algorithm from GenBank. For instance, most Trichoderma isolates found in this study are more closely related to clades reported to be mycotrophs, i.e., T. harzianum and T. koningiopsis species complexes (Chaverri and Samuels, 2013; Chaverri et al., 2015). Therefore, the isolates belonging to Trichoderma were classified as mycotrophs. There were cases in which isolates belonged to clades with different ecological roles (e.g., Fusarium and Purpureocillium). In the case of Fusarium, for which species belonging to all four ecological roles have been reported, isolates were segregated into four groups based on their closest species match. Purpureocillium represented a challenging case because all isolates (based in ITS) were close to P. lilacinus, and this species has been reported to be both a saprobe and an entomopathogen (Luangsa-ard et al., 2011). This genus was eliminated from the ecological analyses (their abundance was not significantly different between management types, so it was not expected to bias the results). The abundance of strains belonging to each of the ecological roles was compared based on their type of management (wild vs. plantation); using similar statistical techniques applied to compare the abundance of each genus (see Statistical Analyses).

\section{Antagonism or competition tests and analyses}


EcoSim ver. 7.72 (Gotelli and Entsminger, 2012) was used to investigate if the endophytic community under study was non-randomly structured, which may suggest interspecific competition or other antagonistic interactions among its components as well as differential use of habitats between taxa. Only non-singleton taxa were used in this analysis. Three communitystructure indices were calculated: C-score, number of checkerboards species pairs, and number of species combinations (= Combo). The C-score measures species segregation (Stone and Roberts, 1990): if the resulting C-score is significantly larger than the one produced by the nulldistribution, then at least some pairs co-occur less often than expected by chance (i.e., taxa are segregated). The reciprocal scenario is also true: if the $\mathrm{C}$-score is less than the one produced by the null model, then more species are co-occurring than expected by chance. An assemblage that is dominated by competition would have taxa that are significantly segregated (i.e., large Cscore); on the contrary, an assemblage dominated by mutualistic interactions would have taxa that are significantly aggregated (i.e., small C-score). The number of checkerboards is defined as the number of species pairs in the matrix that form perfect checkerboards and never co-occur. In a competitively structured community, the observed number of checkerboard species pairs should be significantly larger than expected by chance. The third community structure index, Combo, is the number of unique combinations found between pairs of sites. In a competitively structured community, there should be fewer unique species combinations than by chance (Horner-Devine et al., 2007). Default settings and five thousand iterations were used in the EcoSim analysis. In addition, Pairs ver. 1.0 (Ulrich, 2008) was used to investigate if there were pairs of genera that co-occur more or less frequently than expected by chance. To avoid multiple comparisons, only genera with an abundance of 40 and more were included. One thousand iterations were used in this analysis. Because Trichoderma, a common mycotroph, was the most abundant group in wild trees, correlation tests between its abundance and that of selected plant pathogenic genera were conducted using a two-tailed Spearman's test in SPSS.

Preliminary in vitro antagonism tests were also conducted using 70 Trichoderma cf. harzianum strains against two pathogens of Hevea: Colletotrichum acutatum (strain AF1 from Nigeria) and C. cf. gloeosporioides (strain 'Colle-Mex' from Mexico) (Holliday, 1995; Jayasinghe et al., 1997; Ogbebor et al., 2007). Trichoderma cf. harzianum, a species complex, was selected for the biocontrol experiments because of its well-known antifungal activities (ElHasan et al., 2009; Chen et al., 2012). All the strains that formed a clade and were identified as 
T. cf. harzianum, based on their ITS sequence, were tested. These strains were collected in the wild and in plantations (59 and 11, respectively). Plantations were distributed in Peru (IB), Mexico (MX) and Cameroon (CM); and wild habitats in various locations within Peru (MS, IQ, H, LA, T). For the in vitro antagonism tests, similar methods to Mejía et al. (2008) were used. Briefly, Colletotrichum strains were confronted, in dual plate assays, against Trichoderma strains. Hyphal plugs $(2 \mathrm{~mm} \varnothing)$ of pathogens and endophytes were placed on opposite sides of Petri dishes containing potato dextrose agar. Colletotrichum strains were plated $3 \mathrm{~d}$ earlier due to their slower growth rate. Plates were incubated at constant temperature $\left(25^{\circ} \mathrm{C}\right)$ and under a $12 \mathrm{hr}$ light/dark regime. Evaluation of interactions began $48 \mathrm{hr}$ after endophytes were placed into assay plates. The radius of the colony of each pathogenic strain was measured during the $3 \mathrm{~d}$ after incubation started. Three control plates containing each pathogenic strain alone were kept for reference, and their average colony radius was used in the comparisons. For C. acutatum-T. cf. harzianum tests, three types of activity were evaluated: (1) growth inhibition of the pathogen by the Trichoderma strain; (2) competition for substrate: overgrowth of one organism by another; and (3) mycoparasitism: direct parasitism on the hyphae of the pathogen generally observed as hyphal coiling. If the Trichoderma strain inhibited the growth of the pathogen, showed more radial growth than the pathogen, or parasitized the pathogen, then it is considered preliminary evidence of antagonism. For $C$. cf. gloeosporioides, only growth inhibition tests were done. $C$. acutatum was focused on because of its economic importance and more significant impact in plantations in Asia (Jayasinghe et al., 1997) than those of C. cf. gloeosporioides.

\section{Results}

A total of 190 Hevea trees were surveyed for fungal endophytes; 95 from natural forests in various areas in the Peruvian Amazon and 95 from plantations in Cameroon, Mexico, and Peru. The 2,346 strains collected were classified in 710 putative species (based on 99\% ITS nuclear ribosomal DNA sequence similarity clustering) corresponding to 455 genera; 411 and 404 species in wild and plantation trees, respectively. Fifteen percent of the OTUs were shared between management types, representing 105 species (Table S4 and S6). None of the species accumulation curves reached an asymptote, suggesting that there are still many more endophytic species to be found. However, the curve belonging to the plantation dataset was less steeply

inclined and the projected number of species was less than the one predicted for the wild community (Fig 1). Leaves and sapwood tissue harbored different fungal communities, in terms 
of abundance and species composition, with some genera overlap (Table 1). Diversity was higher in sapwood; whereas abundance was higher in leaves (Fig S1 a-b). Nevertheless, the ecological patterns for the combined datasets (leaves + sapwood), which are described later, were consistent when communities were partitioned by host tissue. Therefore, results presented hereafter refer to the endophytic assemblage inhabiting rubber trees as a whole (leaves + sapwood). Significant results (positive correlation) were only found between tree diameter and the number of OTUs inhabiting the sapwood $(p=0.02)$. There was no correlation between tree diameter or height and the abundance of particular genera.

ANOSIM showed a significant difference in community composition among the management types when all the localities were included $(p \leq 0.0001, R=0.11)$, when Cameroon was excluded $(p \leq 0.0001, R=0.10)$, when Cameroon and Mexico were excluded $(p \leq 0.0003$, $R=0.17$ ), and when only data from $H$. brasiliensis distributed within native range was included $(p \leq 0.0001, R=0.26)$. ANOSIM results using the ecological groups were also significant when all the localities were included $(p \leq 0.0001, R=0.13)$ and when Cameroon was excluded $(p \leq 0.0001$, $R=0.11)$, but not when Cameroon and Mexico were excluded ( $p \leq 0.20, R=0.04)$ nor when only data from $H$. brasiliensis distributed within native range was included $(p \leq 0.06, R=0.07)$. NMDS ordination based on genera composition did not show evidence for aggregation of trees based on management type, when all the localities were included (stress=0.38), when Cameroon was excluded (stress $=0.38$ ), when Cameroon and Mexico were excluded (stress $=0.33$ ), nor when only data from $H$. brasiliensis distributed within native range was included (stress=0.32) (Fig S2 a-d). However, when genera were pooled into ecological groups, NMDS showed evidence for aggregation of trees based on management type, when all the localities were included $($ stress $=0.25)$, when Cameroon was excluded ( excluded (stress $=0.19$ ), and when only data from $H$. brasiliensis distributed within native range was included (stress=0.18) (Fig S3 a-d). PCoA biplots showed the aggregation of trees based on management type when using generic composition (Fig S4 a-d) and ecological grouping (Fig S5 a-d). Differences in community composition between management types were confirmed by the Fast UniFrac analysis $(p \leq 0.001)$, indicating that each community presents a distinct phylogenetic signature.

Significant differences were found in the diversity (richness and abundance) of potentially beneficial endophytic fungi in wild versus plantations trees. Strains of species known 
as mycotrophs or fungal antagonists (e.g., Trichoderma; Harman et al., 2004; Hermosa et al., 2012) and insect pathogens (e.g., Tolypocladium; Samson and Soares, 1984) were significantly more abundant in trees distributed in the wild (Trichoderma Wild $=2.67 /$ tree vs. Plantation $=$ $1.24 /$ tree; Tolypocladium Wild $=0.33 /$ tree vs. Plantation $=0.13 /$ tree; $p \leq 0.001)$ and were positively correlated with that management type ( $p \leq 0.001$; Fig 2 and 3 and Table 1). Overall, the antagonistic fungal genus Trichoderma was the most abundant in wild trees, and not so much in plantation trees (Table 1). In contrast, strains belonging to potentially plant pathogenic species (e.g., Colletotrichum, Fusarium, Guignardia, Lasiodiplodia, and Pestalotiopsis, among others; Holliday, 1995; Jayasinghe et al., 1997; Fernando et al., 2001; Mariau, 2001; Farr and Rossman, 2012) were significantly more abundant in trees in plantations ( $p \leq 0.001$; Fig 2 , Table 1 , and Table S7 and S8), having a positive correlation with that management type ( $p \leq 0.01)$.

The two community-structure indices, C-score and Combo, suggest that further ecological mechanisms may be shaping the community's species composition and abundance (e.g., competition and antagonism, among others). C-score analyses show that the structure of the endophytic community inhabiting Hevea significantly diverges from a random pattern, producing an index larger than expected by chance $(p \leq 0.001)$. The Combo index (number of species combinations) shows that the observed number of species combinations was significantly smaller than expected by chance, presumably because of competition $(p \leq 0.04)$. No significant results were obtained for the number of checkerboard species pairs index $(p=0.52)$. Pairs ver. 1.0 analysis showed that the pair comprising Trichoderma-Guignardia (mycotroph-plant pathogen, respectively) occurred significantly less often than under a null model $(p \leq 0.02)$. Spearsman's rho revealed that the abundance of Trichoderma was negatively correlated with the abundance of the plant pathogenic genus Diaporthe $(p=0.02)$.

Endophytic Trichoderma was negatively correlated with the abundance of endophytic potentially pathogenic genera. The antagonism experiments showed that all Trichoderma strains tested inhibited the growth of both pathogenic Colletotrichum, ranging from $6.3 \%$ to $50 \%$ (Fig 4 and 5 and Table 2). There was no difference in growth inhibition of Colletotrichum spp. by Trichoderma strains from the wild when compared to those from plantations. However, only one strain from plantations reduced the growth of C. acutatum by about $30 \%$ (31.3\%) (Table S9). In contrast, 10 strains from the wild inhibited the growth of the pathogen by $30 \%$ or more (Table S9). In the tests against $C$. cf. gloeosporioides, 11 Trichoderma strains from plantation inhibited 
the growth of the pathogen by 30-40\%; and 52 strains from wild trees inhibited growth by $30-$ $40 \%$ and 2 strains by $40-50 \%$ (Table S10).

There was evidence of competition (overlap or overgrowth of Trichoderma over Colletotrichum), antibiosis (formation of inhibition zone or halo), and mycoparasitism (Trichoderma hyphae coiling around Colletotrichum hyphae)(Fig 6 A-D). $40.7 \%$ and 36.4\% of Trichoderma strains from the wild and plantation, respectively, overlapped or overgrew Colletotrichum, suggesting that competition is the main antagonistic mechanism (Tables S9 and S10). Sixteen (27.1\%) and four (36.4\%) of the confrontations with Trichoderma strains from wild and plantations, respectively, showed a combination of antibiosis and competition. In only $18.6 \%$ of the confrontations with strains from wild trees (none from plantation), was an inhibition zone observed. Mycoparasitism was only clearly observed in three confrontations, one and two Trichoderma strains from plantation and wild, respectively (Fig 6B and C). Even though there was growth inhibition in a few of the tests, neither antibiosis, competition nor mycoparasitim could be clearly determined.

\section{Discussion}

We found that the natural and indigenous endosymbiotic mycota of the rubber tree (Hevea) contains a high diversity of beneficial fungal species that may be causing a protective effect against pathogenic fungi (protective mutualism). In contrast, plantation trees lacked most of these beneficial fungi, thus adding an additional hypothesis behind the causes of disease outbreaks in plantations (or other plant crops). Wild Hevea trees were dominated by strains of the mycotrophic or antagonistic genus Trichoderma and the entomopathogenic genus Tolypocladium (Table 1). A similar trend was also reported by Evans et al. (2003) in wild Theobroma spp. trees distributed in the Amazon basin. Even though Hevea is cultivated in tropical regions, additional factors other than temperature and rainfall likely influence the differences observed between management types. Differences in available inocula and surrounding vegetation (which act as reservoirs of fungal species) are important variables that create a low species overlap between wild and plantation habitats (Helander et al., 2007). The latter confounding factors have not been taken into account in this study as we are solely describing a pattern observed when comparing wild and plantation habitats outside and within the native range of the targeted plant host. Moreover, patterns described here are mainly based 
on hypothesized functional groups, as the OTUs have been assigned an ecological role based on experimental knowledge about their closest relatives. Nevertheless, this research serves as baseline for future testing of ecological hypotheses and encourages the search for natural enemies in native habitats.

We found a significant negative correlation between the abundance of Trichoderma and potentially pathogenic endophytic species (i.e., latent pathogens). Previous studies have shown that Trichoderma can parasitize fungal pathogens, produce antifungal secondary metabolites, outcompete fungal pathogens, promote host growth, and enhance disease resistance in plants (Harman et al., 2004; Hermosa et al., 2012). We, thus, propose that Trichoderma is an important or even essential component in the protection against pathogens in natural forests. We hypothesize that abundance, and not just presence, of competitive Trichoderma strains and species is creating a protective effect against pathogens in wild trees. In our study, trees in the wild had ca. $2.5 \times$ more Trichoderma strains than trees in plantations. This supports a "multiple defender effect" hypothesis, which was first described for corals and their mutualistic crustaceans (McKeon et al., 2012). The multiple defender effect hypothesis states that the presence of multiple mutualists creates a more synergistic, additive and protective effect than just the presence of one of them. Another study concluded that the combined effects of arbuscular mycorrhizal fungi and fungal endophytes on plant growth were additive (Larimer et al., 2012). In our antagonism tests, even though there were no differences in average growth inhibition by $T$. harzianum against $C$. acutatum and $C$. gloeosporioides, the majority of the strains from wild trees had a much stronger inhibitory effect (30-50\%).

Although with lower incidence than in sapwood (Table 1), Trichoderma isolates were also recovered from living leaf tissue. The latter contradicts studies targeting Coffea arabica, for which Trichoderma was shown to inhabit its rhizosphere but was not recovered as a leaf endophyte (Mulaw et al., 2010, Vega et al., 2010, Mulaw et al., 2013). However, these other studies were conducted in different geographic regions and following different protocols. On the other hand, other studies targeting tropical trees such as Guarea guidonia (Gamboa and Bayman, 2001) and Manilkara bidentata (Lodge et al., 1996), support our findings. Furthermore, experimental assays have demonstrated that certain Trichoderma species can enter and migrate from the soil to the above ground tissue (including leaves) through the root system (Bailey et al., 2008) or from the air to trichomes to the leaf tissue (Bailey et al., 2009). 
Strains with a predicted entomopathogenic ecological role were also significantly more abundant in wild trees $(p \leq 0.001$, Table 1$)$, almost double than in plantations. Most of these strains belonged to the genus Tolypocladium, which is known to deter and parasitize diverse groups of insects (Samson and Soares, 1984), especially those that feed on plant roots (e.g., cicada nymphs and scarab beetle larvae). Previous research has shown that entomopathogenic fungi can become endophytic (i.e., Beauveria, Metarhizium, Purpureocillium) (Evans et al., 2003; Vega et al., 2008) but their potential role as mutualists has not been widely tested.

Tolypocladium species have been screened for their potential applications in biological control of crop pests, showing promise in the control of some cacao fungal diseases and pest aphids (Hanada et al., 2010; Scorsetti et al., 2012). Even though we did not test the Tolypocladium strains isolated in this study, based on their close phylogenetic relationship to species with known entomopathogenic properties (Gazis et al., 2014), we considered them as potential candidates for future biocontrol assays against Hevea pests (e.g., the litter beetle Luprops tristis, mites of the family Eriophyidae and Tenuipalpus, and the lace bug Leptopharsa hevae) (Sabu and Vinod, 2009; Santos, 2010). It is believed that the primary mechanism of insect deterrence is through the production of secondary metabolites (Vega et al., 2008; Ownley et al., 2010).

Besides the multiple defender hypothesis explained earlier, the causes behind the absence of severe epiphytotics in tropical forests can also be explained through two other evolutionary hypotheses. The "arms race" hypothesis states that hosts and pathogens are in a constant coevolutionary cycle in which resistance is acquired by the host and overcome by the pathogen through time. This cycle creates a fluctuation in both host and pathogen populations that act as a balancing force for their coexistence (Van Valen, 1973; Maor and Shirazu, 2005). The "mutualist facilitation" hypothesis also supports our results. This hypothesis contends that the replacement of lost mutualists/commensals (e.g., Trichoderma and Tolypocladium) from plants' native ranges with new mutualists/commensals in their introduced ranges is important for the establishment and success of introduced plants (Mitchell et al., 2006). Changes in mutualistic species composition may limit success or even prevent establishment and naturalization of a plant in a new area if the pool of mutualists available to it does not include species with which it coevolved (Klironomos, 2003). In addition, differences in species composition between plants' native and introduced ranges may be biased either towards or against successful introduction of the plant to 
the new area (Parker and Hay, 2005). Such biases arise because a plant species shares a longer co-evolutionary history with a specific assemblage of mutualists/commensals in its native range than in its introduced range.

We believe that multiple factors act in concert to create a complex scenario in which pathogens and their plant hosts coexist in balance. Environmentally compatible and sustainable plant disease control practices should attempt to recreate this setting. One strategy is to introduce multiple protective endosymbionts, such as fungi (Jones, 2013) but also bacteria (Compant et al., 2010), from a host's native habitat, analogous to the use of probiotics to improve health in humans or other animals (Fraga et al., 2011; Berlec, 2012; Alonso and Guarner, 2013). These species should have high specificity to their hosts or prey that is supported by a long-shared evolutionary history. Endosymbionts with antagonistic properties against pathogens that affect rubber trees could be inoculated in seedlings before they are grown in plantations (Bailey et al., 2008). This strategy, in addition to other practices such as resistance breeding programs, promoting stands composed by individuals with heterogeneous genetic background and quarantine regulations to prevent the spread of endemic pests, should be undertaken as an integrated pest control management for natural rubber production.

This research emphasizes the importance of endosymbionts as an ecological service derived from natural forests. Each year, extensive areas of Amazonian forest are destroyed as a consequence of human activities (Almeyda Zambrano et al., 2010). Deforestation results in the loss of valuable endemic species from all Kingdoms of life, of which many have the potential for providing valuable ecosystem services. With these vanishing areas, we are losing the chance of discovering, bioprospecting and later exploiting an uncountable number of species unknown to science. Studies that aim to uncover the value and utility of species that are of microscopic size, have a microhabitat specialization and act as obligate symbionts with their hosts, promote the value of sustaining native tropical forests.

\section{ACKNOWLEDGEMENTS}

As this article compiles research conducted through several years and in many localities, we are thankful to various people who in one way or another have participated in the success of this project. We are very grateful to: Akiko Hirooka (UMD), Aurelie Mandengue (Cameroon), Dr. Amy Y. Rossman (USDA), Dr. Daniel Gruner (UMD), Daniella Biffi (Peru), Demetra Skaltsas 
(UMD), Dr. Enrique Arevalo (ICT, Peru), Dr. Gary J. Samuels (USDA), Dr. Harry C. Evans (CABI), Ikenna Okafor (UMD), Janette Barrios (Peru), Peter O'Halloran (UMD), Dr. Maribel Domingues-Domingues (Mexico), Maribel Espinoza (Peru), and Dr. Stephen Rehner (USDA). This project was funded by NSF grants DEB-925672 and DEB-1019972 to P. Chaverri, and grants from the Amazon Conservation Association and the Latin American Studies Center (UMD) to R. Gazis. R. Gazis worked on this article while a postdoctoral fellow in the Open Tree of Life project, supported by the NSF DEB-12008809 given to D. Hibbett.

\section{REFERENCES}

Almeyda Zambrano, A.M., Broadbent, E.N., Schmink, M., Perz, S.G., Asner, G.P., 2010. Deforestation drivers in southwest Amazonia: Comparing smallholder farmers in Iñapari, Peru and Assis Brasil, Brazil. Conservat. Soc. 8, 157-170.

Alonso, V.R., Guarner, F., 2013. Linking the gut microbiota to human health. Brit. J. Nutr. 109, 21-26.

Arnold, A.E., Herre, E.A., 2003. Canopy cover and leaf age affect colonization by tropical fungal endophytes: ecological pattern and process in Theobroma cacao (Malvaceae). Mycologia 95, 388-398.

Arnold, A.E., Maynard, Z., Gilbert, G.S., Coley, P.D., Kursar, T.A., 2000. Are tropical endophytes hyperdiverse? Ecol. Lett. 3, 267-274.

Bailey, B.A., Bae, H., Strem, M.D., Crozier, J., Thomas, S.E., Samuels, G.J., Vinyard, B.T., Holmes, K.A., 2008. Antibiosis, mycoparasitism, and colonization success for endophytic Trichoderma strains with biological control potential in Theobroma cacao. Biol. Control 46, 2435.

Bailey, B.A., Strem, M.D., Wood, D., 2009. Trichoderma species form endophytic associations within Theobroma cacao trichomes. Mycol. Res. 113,1365-1376.

Berlec, A., 2012. Novel techniques and findings in the study of plant microbiota: Search for plant probiotics. Plant Sci. 193-94, 96-102. 
Blaser, M.J., Falkow, S., 2009. What are the consequences of the disappearing human microbiota? Nat. Rev. Microbial. 7, 887-894.

Carbone, I., Kohn, L.M., 1999. A method for designing primer sets for speciation studies in filamentous ascomycetes. Mycologia 91, 553-556.

Chao, A., Colwell, R.K., Lin, C.W., Gotelli, N.J., 2009. Sufficient sampling for asymptotic minimum species richness estimators. Ecology 90, 1125-1133.

Chaverri, P., Branco-Rocha, F., Jaklitsch, W., Gazis, R., Degenkolb, T., Samuels, G.J., 2015. Systematics of the Trichoderma harzianum species complex and the reidentification of commercial biocontrol strains. Mycologia (In Press). doi: 10.3852/14-147.

Chaverri, P., Samuels, G.J., 2013. Evolution of habitat preference and nutrition mode in a cosmopolitan fungal genus with evidence of interkingdom host jumps and major shifts in ecology. Evolution 7, 2823-2837.

Chen, L.H., Huang, X.Q., Zhang, F.G., Zhao, D.K., Yang, X.M., Shen, Q.R., 2012. Application of Trichoderma harzianum SQR-T037 bio-organic fertilizer significantly controls Fusarium wilt and affects the microbial communities of continuously cropped soil of cucumber. J. Sci. Food Agr. 92, 2465-2470.

Colwell, R.K., 2005. EstimateS: Statistical estimation of species richness and shared species from samples. Version 7.5. URL http://purl.oclc.org/estimates.

Colwell, R.K., Mao, C.X., Chang, J., 2004. Interpolating, extrapolating, and comparing incidence-based species accumulation curves. Ecology 85, 2717-2727.

Compant, S., Clement, C., Sessitsch, A., 2010. Plant growth-promoting bacteria in the rhizo- and endosphere of plants: Their role, colonization, mechanisms involved and prospects for utilization. Soil Biol. Biochem. 42, 669-678.

El-Hasan, A., Walker, F., Schöne, J., Buchenauer, H., 2009. Detection of viridiofungin A and other antifungal metabolites excreted by Trichoderma harzianum active against different plant pathogens. Eur. J. Plant Pathol. 124, 457-470.

Evans, H.C., 2008. The endophyte-enemy release hypothesis: implications for classical biological control and plant invasions, in: Julien, M.H., Sforza, R., Bon, M.C., Evans, H.C., 
Thatcher, P.E., Hinz, H.L., Rector, B.G. (Eds.), Proceedings of the Twelfth International Symposium on Biological Control of Weeds. CAB International, Wallingford, pp. 20-25.

Evans, H.C., Holmes, K.A., Thomas, S.E., 2003. Endophytes and mycoparasites associated with an indigenous forest tree, Theobroma gileri, in Ecuador and a preliminary assessment of their potential as biocontrol agents of cocoa diseases. Mycol. Prog 2, 149-160.

Farr, D.F., Rossman, A.Y., 2012. Fungal Databases, Systematic Mycology and Microbiology Laboratory, ARS, USDA. URL http://nt.ars-grin.gov/fungaldatabases/index.cfm.

Fernando, T.H.P.S., Jayasinghe, C.K., Wijesundera, R.L.C., 2001. Cell wall degrading enzyme secretion by Colletotrichum acutatum the causative fungus of secondary leaf fall of Hevea brasiliensis. Mycol. Res. 105, 195-201.

Fraga, M., Perelmuter, K., Delucchi, L., Zunino, P., 2011. Equine native microbiota as a source of beneficial microbes, in: Leffhalm, J.E. (Ed.) Horses: Biology, domestication and human interactions. Nova Science Publishers, New York, pp. 111-120.

Gamboa, M.A., Bayman, P., 2001. Communities of endophytic fungi in leaves of a tropical timber tree (Guarea guidonia: Meliaceae). Biotropica 33, 352-360.

Gazis, R., Chaverri, P., 2010. Diversity of fungal endophytes in leaves and stems of wild rubber trees (Hevea brasiliensis) in Peru. Fungal Ecol. 3, 240-254.

Gazis, R., Rehner, S., Chaverri, P., 2011. Species delimitation in fungal endophyte diversity studies and its implications in ecological and biogeographic inferences. Mol. Ecol. 20, 30013013.

Gazis, R., Skaltsas, D., Chaverri, P., 2014. Novel endophytic lineages of Tolypocladium provide new insights into the ecology and evolution of Cordyceps-like fungi. Mycologia 106, 1090-1105.

Gotelli, N.J., Entsminger, G.L., 2012. EcoSim 7.72. Acquired Intelligence, Inc. URL http://www.uvm.edu/ ngotelli/EcoSim/EcoSim.html.

Hamady, M., Lozupone, C., Knight, R., 2010. Fast UniFrac: facilitating high-throughput phylogenetic analyses of microbial communities including analysis of pyrosequencing and PhyloChip data. The ISME journal 4, 17-27. 
Hammer, O., Harper, D.A.T., Ryan, P.D., 2001. PAST: Paleontological Statistics package for education and data analysis. Palaeontol. Electron. 4.

Hanada, R.E., Pomella, A.W.V., Salazar Costa H., Bezerra, J.L., Loguercio, L.L., Pereira, J.O., 2010. Endophytic fungal diversity in Theobroma cacao (cacao) and T. grandiflorum (cupuaçu) trees and their potential for growth promotion and biocontrol of black-pod disease. Fungal Biol. 114, 901-910.

Harman, G.E., Howell, C.R., Viterbo, A., Chet, I., Lorito, M., 2004. Trichoderma species Opportunistic, avirulent plant symbionts. Nat. Rev. Microbiol. 2, 43-56.

Helander, M., Ahlholm, J., Sieber, T.N., Hinneri, S., Saikkonen, K., 2007. Fragmented environment affects birch leaf endophytes. New Phytol. 175, 547-553.

Hermosa, R., Viterbo, A., Chet, I., Monte, E., 2012. Plant-beneficial effects of Trichoderma and of its genes. Microbiology 158, 17-25.

Holliday, P., 1995. Fungus diseases of tropical crops. Dover Publications, New York.

Horner-Devine, M.C., Silver, J.M., Leibold, M.A., Bohannan, B.J.M., Colwell, R.K., Fuhrman, J.A., Green, J.L., Kuske, C.R., Martiny, J.B.H., Muyzer, G., Øvreås, L., Reysenbach, A-L., Smith, V.H., 2007. A comparison of taxon co-occurrence patterns for macro-and microorganisms. Ecology 88, 1345-1353.

Jayasinghe, C.K., Fernando, T.H.P.S., Priyanka, U.M.S., 1997. Colletotrichum acutatum is the main cause of Colletotrichum leaf disease of rubber in Sri Lanka. Mycopathologia 137, 53-56.

Jones, N., 2013. Food fuelled with fungi. Nature 504, 199.

Katoh, K., Hiroyuki, T., 2008. Recent developments in the MAFFT multiple sequence alignment program. Brief. Bioinform. 9, 286-298.

Kikuchi, Y., Hosokawa, T., Fukatsu, T., 2007. Insect-microbe mutualism without vertical transmission: a stinkbug acquires a beneficial gut symbiont from the environment every generation. Appl. Environ. Microb. 73, 4308-4316.

Klironomos, J.N., 2003.Variation in plant response to native and exotic arbuscular mycorrhizal fungi. Ecology 84, 2292-2301. 
Larimer, A.L., Bever, J.D., Clay, K., 2012. Consequences of simultaneous interactions of fungal endophytes and arbuscular mycorrhizal fungi with a shared host grass. Oikos 121, 2090-2096.

Lodge, D.J., Fisher, P.J., Sutton, B.C., 1996. Endophytic fungi of Manilkara bidentata leaves in Puerto Rico. Mycologia 88, 733-738.

Luangsa-ard, J., Houbraken, J., van Doorn, T., Hong, S-B., Borman, A.M., Hywel-Jones, N., Samson, R.A., 2011. Purpureocillium, a new genus for the medically important Paecilomyces lilacinus. FEMS Microbiol. Lett. 321, 141-149.

Maddison, W.P., Maddison, D.R., 2009. Mesquite: a modular system for evolutionary analysis. Version 2.6. URL http://mesquiteproject.org.

Maor, R., Shirasu, K., 2005. The arms race continues: battle strategies between plants and fungal pathogens. Curr. Opin. Microbiol. 8, 399-404.

Mariau, D., 2001. Diseases of tropical tree crops. Science Publishers, New Hampshire. McKeon, C.S., Stier, A.C., McIlroy, S.E., Bolker, B.M., 2012. Multiple defender effects: synergistic coral defense by mutualist crustaceans. Oecologia 169, 1095-1103.

Mejía, L.C., Rojas, E.I., Maynard, Z., Van Bael, S., Arnold, A.E., Hebbar, P., Samuels, G.J., Robbins, N., Herre, E.A., 2008. Endophytic fungi as biocontrol agents of Theobroma cacao pathogens. Biol. Control 46, 4-14.

Mitchell, C.E., Agrawal, A.A., Bever, J.D., Gilbert, G.S., Hufbauer, R.A., Klironomos, J.N., Maron, J.L., Morris, W.F., Parker, I.M., Power, A.G., Seabloom, E.W., Torchin, M.E., Vázquez, D.P., 2006. Biotic interactions and plant invasions. Ecol. Lett. 9, 726-740.

Mulaw, T.B., Druzhinina, I.S., Kubicek, C.P., Atanasova, L., 2013. Novel endophytic Trichoderma spp. isolated from healthy Coffea arabica roots are capable of controlling coffee tracheomycosis. Diversity 5, 750-766.

Mulaw, T.B., Kubicek, C.P., Druzhinina, I. S., 2010. The rhizosphere of Coffea arabica in its native highland forests of Ethiopia is associated with a distinguished diversity of Trichoderma. Diversity 2, 527-549. 
Ogbebor, N.O., Adekunle, A.T., Enobakhare, D.A., 2007. Inhibition of Colletotrichum gloeosporioides (Penz) Sac. causal organism of rubber (Hevea brasiliensis Muell. Arg.) leaf spot using plant extracts. Afr. J. Biotechnol. 6, 213-218.

Ownley, B.H., Gwinn, K.D., Vega, F.E., 2010. Endophytic fungal entomopathogens with activity against plant pathogens: Ecology and evolution. BioControl 55, 113-128.

Parker, J.D., Hay, M.E., 2005. Biotic resistance to plant invasions? Native herbivores prefer nonnative plants. Ecol. Lett. 8, 959-967.

Rehner, S., 2001. Primers for Elongation Factor 1-a (EF1-a). Available at http://ocid. NACSE. ORG/research/deephyphae.

Rodriguez, R.J., White, J.F., Arnold, A.E., Redman, R.S., 2009. Fungal endophytes: Diversity and functional roles. New Phytol. 182, 314-330.

Rojas, E.I., Rehner, S.A., Samuels, G.J., Van Bael, S.A., Herre, E.A., Cannon, P., Chen, R., Pang, J., Wang, R., Zhang, R., Peng, Y-Q., Sha, T., 2010. Colletotrichum gloeosporioides s.1. associated with Theobroma cacao and other plants in Panamá: multilocus phylogenies distinguish host-associated pathogens from asymptomatic endophytes. Mycologia 102, 13181338.

Round, J.L., Mazmanian, S.K., 2009. The gut microbiota shapes intestinal immune responses during health and disease. Nat. Rev. Immunol. 9, 313-323.

Rubini, M.R., Silva-Ribeiro, R.T., Pomella, A.W., Maki, C.S., Araújo, W.L., Dos Santos, D. R., Azevedo, J.L., 2005. Diversity of endophytic fungal community of cacao (Theobroma cacao L.) and biological control of Crinipellis perniciosa, causal agent of Witches' Broom Disease. Int. J. Biol. Sci. 1, 24.

Sabu, T.K., Vinod, K.V., 2009. Population dynamics of the rubber plantation litter beetle Luprops tristis, in relation to annual cycle of foliage phenology of its host, the para rubber tree, Hevea brasiliensis. J. Insect. Sci. 9, 56.

Saikkonen, K., Faeth, S.H., Helander, M., Sullivan, T.J., 1998. Fungal endophytes: A continuum of interactions with host plants. Annu. Rev. Ecol. Syst. 29, 319-343. 
Samson, R.A., Soares, G.G., 1984. Entomopathogenic species of the hyphomycete genus Tolypocladium. J. Invertebr. Pathol. 43, 133-139.

Santos, R.S., 2010. Biological control of rubber tree lace bug by endophytic parasitoid in Brazil. Entomology papers from other sources Paper 114.

Saucedo-García, A., Anaya, A.L., Espinosa-García, F.J., González, M.C., 2014. Diversity and communities of foliar endophytic fungi from different agroecosystems of Coffea arabica L. in two regions of Veracruz, Mexico. PloS one 9, e98454.

Schloss, P.D., Westcott, S.L., Ryabin, T., Hall, J.R., Hartmann, M., Hollister, E.B., Lesniewski, R.A., Oakley, B.B., Parks, D.H., Robinson, C., 2009. Introducing mothur: Open source, platform-independent, community-supported software for describing and comparing microbial communities. Appl. Environ. Microb. 75, 7537-7541.

Scorsetti, A.C., Elíades, L.A., Stenglein, S.A., Cabello, M.N., Pelizza, S.A., Saparrat, M.C.N., 2012. Pathogenic and enzyme activities of the entomopathogenic fungus Tolypocladium cylindrosporum (Ascomycota: Hypocreales) from Tierra del Fuego, Argentina. Rev. Biol. Trop. 60, 833-841.

Sears, C.L., 2005. A dynamic partnership: Celebrating our gut flora. Anaerobe 11, 247-251.

Shultes, R.E., 1970. The history of taxonomic studies in Hevea. Bot. Rev. 36, 197-276.

Stone, L., Roberts, A., 1990. The checkerboard score and species distributions. Oecologia 85, 74-79.

Ulrich, W., 2008. Pairs - a FORTRAN program for studying pair-wise species associations in ecological matrices. URL www.uni.torun.pl/ ulrichw.

Van Valen, L., 1973. A new evolutionary law. Evol. Theor. 1, 1-30.

Vega, F.E., Posada, F., Aime, M.C., Pava-Ripoll, M., Infante, F., Rehner, S.A., 2008.

Entomopathogenic fungal endophytes. Biol. Control 46, 72-82.

Vega, F.E., Simpkins A., Aime M.C., Posada F., Peterson S.W., Rehner S.A., Infante F., Castillo A., Arnold A.E., 2010. Fungal endophyte diversity in coffee plants from Colombia, Hawai'i, Mexico and Puerto Rico. Fungal Ecol. 3, 122-138. 
White, T.J., Bruns, T., Lee, S.J.W.T., Taylor, J.W., 1990. Amplification and direct sequencing of fungal ribosomal RNA genes for phylogenetics, in: Innis, M.A., Gelfand, D.H., Sninsky, J.J., White, T.J. (Eds), PCR protocols: a guide to methods and applications. Academic Press, San Diego, pp. 315-322.

\section{$\underline{\text { Figure Legends }}$}

Figure 1. Species accumulation curves. Y-axis shows the $95 \%$ confidence interval (CI) of the Species Observed (Sobs). The projected number of species was estimated based on CHAO 1 and was calculated for the lowest common amount of strains (883). The projected total number of species $(*)$ for the wild dataset is $1060 \pm 19.47$, whereas for the plantation dataset is $932 \pm 82.37$. Curves were made in EstimateS and plotted in SPSS.

Figure 2. Comparison of the mean abundance per tree for strains that showed significant differences between management regimes $(\mathrm{M}=$ mycotroph, $\mathrm{P}=$ plant pathogen, $\mathrm{E}=$ entomopathogen). Only genera that showed abundance higher than 40 individuals were used in this analysis.

Figure 3. Species accumulation curves for (A) mycotrophs, (B) entomopathogens and (C) plant pathogens.

Figure 4. Results from antagonistic assays. (A) Growth inhibition results from the confrontation assays using Trichoderma strains against Colletotrichum acutatum (AF1).

Figure 5. Growth inhibition in the confrontations assays using Trichoderma strains against Colletotrichum cf. gloeosporoides ("Colle-Mex").

Figure 6. Examples of antagonism. (A) A 7d culture of Colletotrichum acutatum (strain AF1) growing in PDA; (B) Dual culture of Trichoderma strain IQ214 against C. acutatum (strain 
AF1), showing the formation of inhibition halo; (C) Dual culture of Trichoderma strain MS173 against C. acutatum (strain AF1), showing Trichoderma overgrowing C. acutatum and sporulating over its colony; and (D) Micrograph of a section from a dual culture of Trichoderma MS173 against $C$. acutatum (strain AF1), showing the coiling of the Trichoderma hyphae around C. acutatum hyphae. 
Table 1. Genera that showed significant differences in their abundance per tree, based on their type of management. Significance was only calculated for the estimates per tree, using the nonparametric Mann-Whitney implemented in SPSS (U), and is denoted by bold font. N represents the number of independent samples used in each analysis. Four localities were sampled for each management type, encompassing a total of 190 individual trees (95 trees in each management type).

\begin{tabular}{|c|c|c|c|c|c|c|c|c|c|}
\hline & \multicolumn{3}{|c|}{$\begin{array}{c}\text { Abundance } \\
(\mathrm{N}=4)\end{array}$} & \multicolumn{2}{c|}{$\begin{array}{c}\text { Mean / per tree } \\
(\mathrm{N}=95)\end{array}$} & \multicolumn{2}{c|}{$\begin{array}{c}\text { Mean / per tree } \\
\text { / sapwood } \\
(\mathrm{N}=95)\end{array}$} & \multicolumn{2}{c|}{$\begin{array}{c}\text { Mean / per tree } \\
\text { / leaf } \\
(\mathrm{N}=60)\end{array}$} \\
\hline & $\mathrm{T}$ & $\mathrm{W}$ & $\mathrm{M}$ & $\mathrm{W}$ & $\mathrm{M}$ & $\mathrm{W}$ & $\mathrm{M}$ & $\mathrm{W}$ & $\mathrm{M}$ \\
\hline Colletotrichum & 209 & 61 & 148 & 0.64 & $\underline{\mathbf{1 . 5 6}}$ & 0.05 & 0.09 & 1.08 & $\underline{\mathbf{2 . 3 5}}$ \\
\hline Entonaema & 13 & 1 & 12 & 0.01 & $\underline{\mathbf{0 . 1 3}}$ & 0.00 & 0.00 & 0.02 & $\underline{\mathbf{0 . 2 0}}$ \\
\hline Fusarium & 108 & 36 & 72 & 0.38 & $\underline{\mathbf{0 . 7 6}}$ & 0.25 & $\underline{\mathbf{0 . 5 4}}$ & 0.24 & 0.37 \\
\hline Guignardia & 80 & 14 & 66 & 0.15 & $\underline{\mathbf{0 . 6 9}}$ & 0.03 & 0.05 & 0.24 & $\underline{\mathbf{1 . 0 3}}$ \\
\hline Lasiodiplodia & 38 & 8 & 30 & 0.08 & $\underline{\mathbf{0 . 3 2}}$ & 0.03 & $\underline{\mathbf{0 . 2 8}}$ & 0.10 & 0.05 \\
\hline Paraconiothyrium & 6 & 6 & 0 & $\underline{\mathbf{0 . 0 6}}$ & 0.00 & $\underline{\mathbf{0 . 0 4}}$ & 0.00 & 0.02 & 0.00 \\
\hline Pestalotiopsis & 152 & 66 & 86 & 0.69 & $\underline{\mathbf{0 . 9 1}}$ & 0.26 & $\underline{\mathbf{0 . 7 9}}$ & $\underline{\mathbf{0 . 8 0}}$ & 0.21 \\
\hline Tolypocladium & 43 & 31 & 12 & $\underline{\mathbf{0 . 3 3}}$ & 0.13 & $\underline{\mathbf{0 . 3 3}}$ & 0.13 & 0.00 & 0.00 \\
\hline Trichoderma & 372 & 254 & 118 & $\underline{\mathbf{2 . 6 7}}$ & 1.24 & $\underline{\mathbf{2 . 3 2}}$ & 1.05 & $\underline{\mathbf{0 . 7 5}}$ & 0.27 \\
\hline
\end{tabular}

Abbreviations: $\mathrm{T}=$ total (wild + managed); $\mathrm{W}=$ wild $; \mathrm{M}=$ managed . 
Table 2. Number (\#) and percentage of $T$. cf. harzianum strains with antagonistic activities (antibiosis, competition, growth inhibition, and mycoparasitism) against $C$. acutatum.

\begin{tabular}{|l|c|c|}
\hline & \multicolumn{2}{|c|}{ Origin of Trichoderma strain } \\
\hline & Wild & Plantation \\
\hline Activity & $\# \mathbf{( \% )}$ & $\#(\mathbf{\% )}$ \\
\hline Growth inhibition & $59(100)$ & $11(100)$ \\
\hline Only competition (overlap) & $24(40.7)$ & $4(36.4)$ \\
\hline Only antibiosis (inhibition zone) & $11(18.6)$ & 0 \\
\hline Antibiosis and competition & $16(27.1)$ & $1(36.4)$ \\
\hline $\begin{array}{l}\text { Antibiosis, competition, and } \\
\text { mycoparasitism }\end{array}$ & $2(3.4)$ & $2(18.2)$ \\
\hline $\begin{array}{l}\text { No antibiosis, competition or } \\
\text { mycoparasitism observed }\end{array}$ & $12(20.3)$ & $\mathbf{1 1}(\mathbf{1 0 0 )}$ \\
\hline TOTAL & $\mathbf{5 9 ( 1 0 0 )}$ & \\
\hline
\end{tabular}




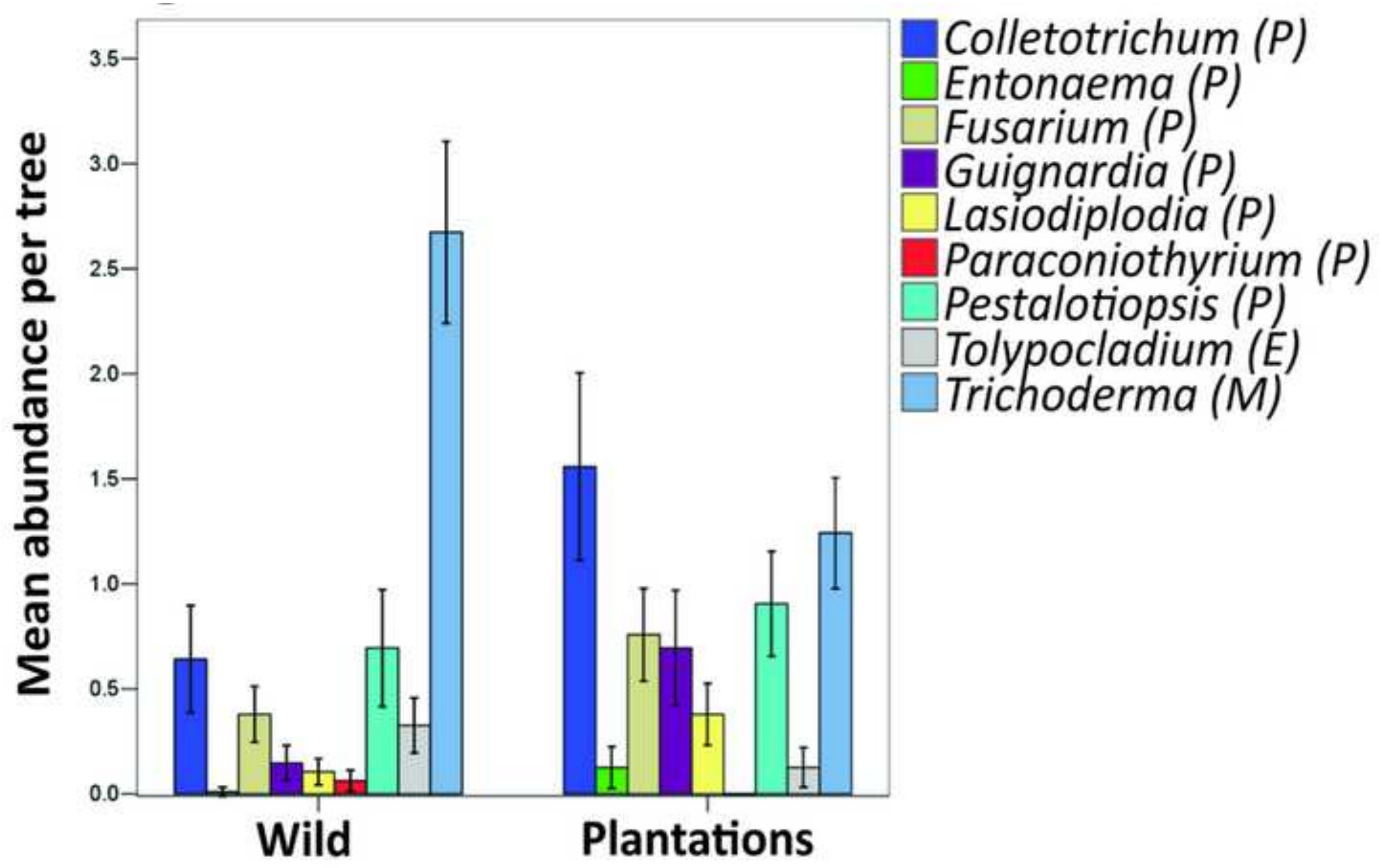



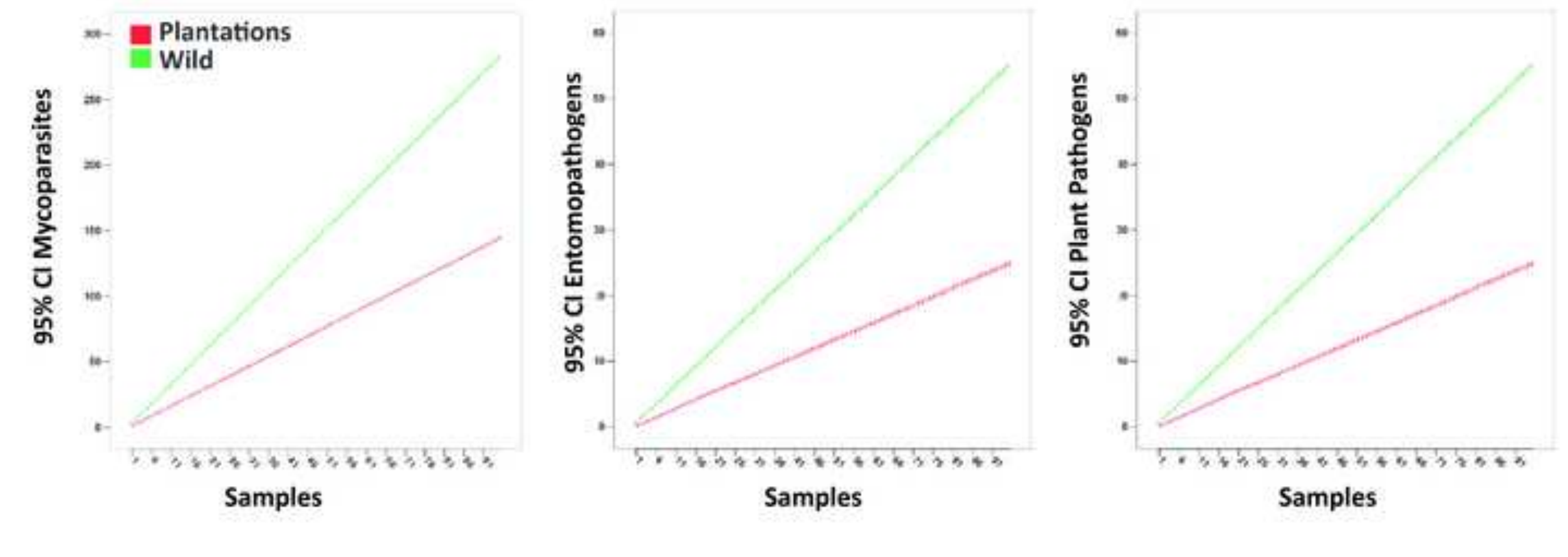
Figure
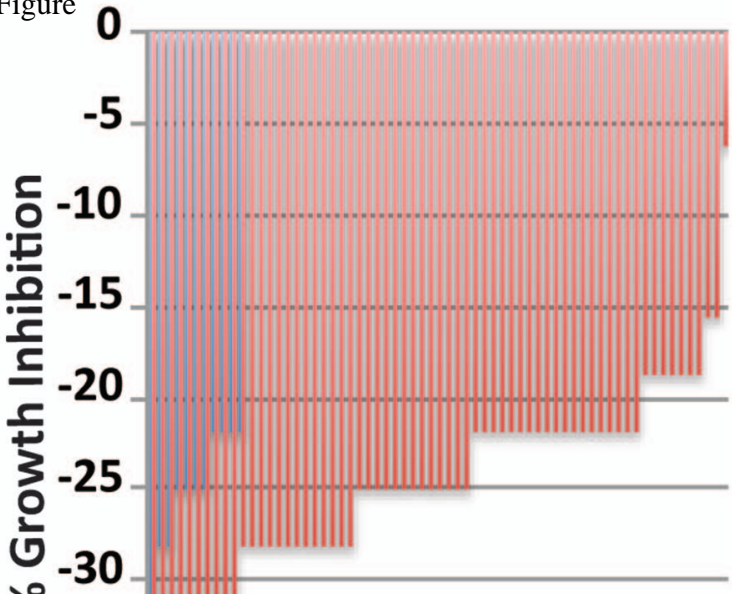

de

-

IIIII

$-40$

Wild

- Plantation 

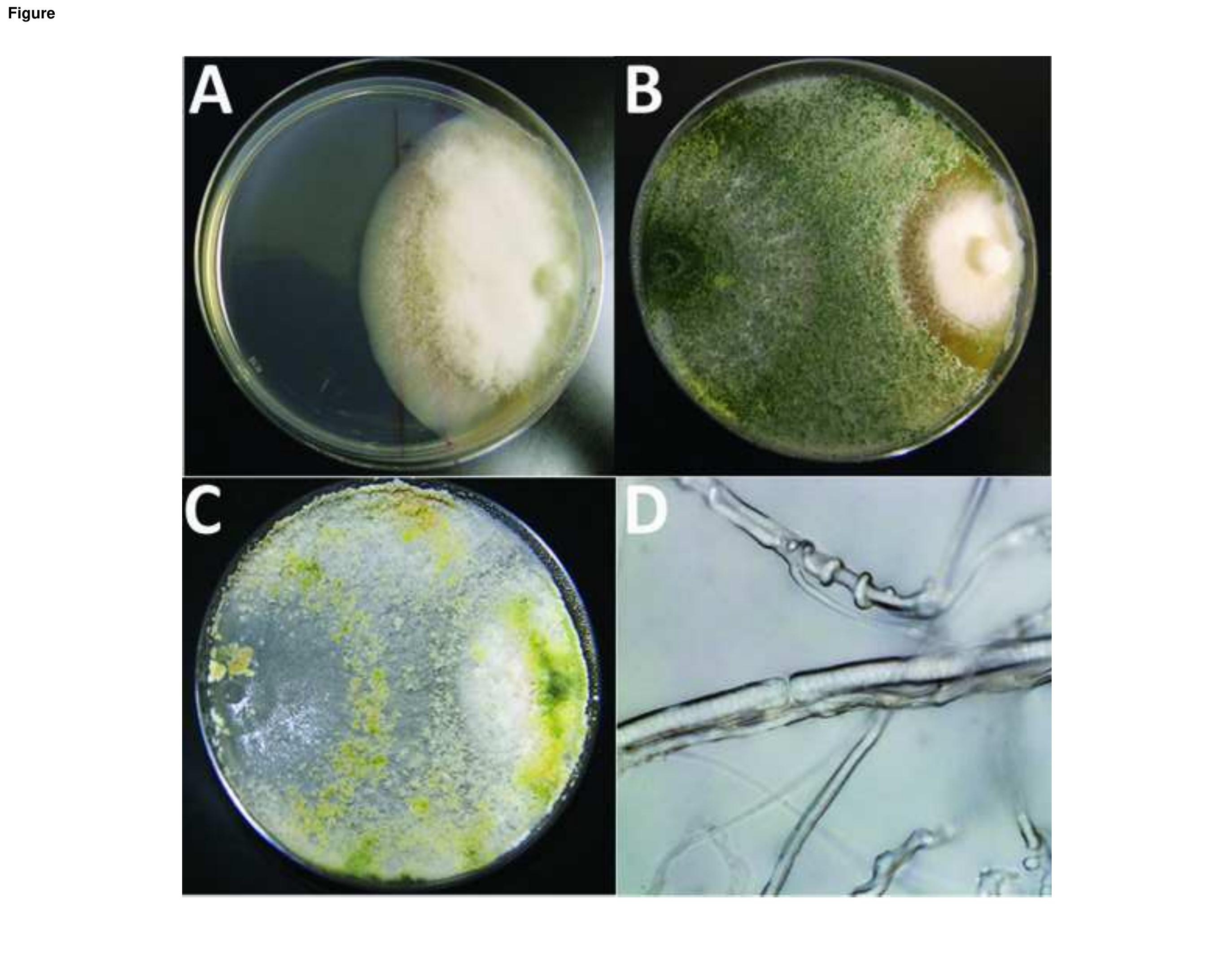